\title{
Infant Feeding Pattern and Practices among Lactating Mothers in Santa Fe, Romblon
} Philippines

\author{
Ken N Falculan ${ }^{1}$, Ralph N Falculan ${ }^{2}$ \\ Email: ken.falculan@1spu.edu.ph \\ ${ }^{1}$ Assistant Professor, Romblon State University, Odiongan, Romblon \\ ${ }^{2}$ Development Management Officer, Department of Health- MIMAROPA \\ Received: November 2, 2021 \\ Received in Revised: November 30, \\ 2021 \\ Accepted: December 6, 2021
}

\begin{abstract}
This paper examines whether the profile of the respondents: age, number of living children, marital status, income status, employment status, educational background, current feeding practices, and level of knowledge on the importance of EBF affects feeding among infants 0-6 months old. The study uses a descriptive analysis using a normative survey with a study population of 102 mothers from the Municipality of Santa Fe Romblon respondents who were informed and given consent to secure. The result is as follows mothers, whose age ranges from 21 to 25 , are the most prevailing, 39\%, of the total respondents are practicing EBF. The more children the respondent had higher the percentage of practicing EBF, 55\% of respondents say; they are living in with a partner, either married through church wedding, civil or in the state of cohabitation, lower-income mothers (45\%) practice EBF more compared to other income class. Mothers without job practice EBF more (51\%) exclusive breastfeeding are practiced more by elementary graduate mothers (63\%), forty-four (44) mothers out of one hundred two (102) respondents are doing exclusive breastfeeding, at least $63 \%$ have revealed little knowledge on the importance of exclusive feeding.
\end{abstract}

Keywords: Breastfeeding, Neurophysiological, Nuclear Family, Premature Babies

\section{Introduction}

Breast milk is best for our baby, and the benefits of breastfeeding extend well beyond primarily in nutrition (Segura et al., 2016). In contrast, the vitamins and nutrients, baby needs in the first six months of life are breast-milk is free with disease-fighting substances that protect our baby from illness. It was recommended to breastfeed for the first six months (although any amount of breastfeeding is beneficial. And scientific studies have shown that breastfeeding is good for our health. Breastfeeding protects babies from illnesses and protects them from developing allergies and obesity that may boost the child's intelligence (Nadeem et al., 2017; Kukla, 2006). Breastfeeding can reduce a mother's stress level and risk of postpartum depression (LaraCinisomo et al., 2017). According to a report that women feel relaxed while breastfeeding, it may also reduce cancer in women. Recommended that infants will be exclusively be breastfed for the first six months of life to achieve optimal growth, development, and health, the appropriate age at which solid food is about to introduce is around six months owing to the immaturity of the gastrointestinal tract and the renal system as well as on the neurophysiological status of the infant. Hospitals and maternity units set a powerful example for new mothers (Brown et al., 2005). A maternity facility can be designated baby-friendly when it does not accept free or low-cost breast milk substitutes, feeding bottles, or teats and has implemented ten specific steps to support successful breastfeeding. 


\section{Methods}

The researcher will be using the descriptive method of research. These are fact-finding studies. It is otherwise known as a normative survey utilized to collect demographic data about people's practices, beliefs, intentions, opinions, attitudes, interests, perceptions, and each data will be analyzed, organized, and interpreted (Calderon, 2003).

\section{Respondents of the Study}

The respondents of this study included one hundred two mothers from the Municipality of Santa Fe, Romblon.

\section{Research Instrument}

A structured questionnaire will be the gathering device used to obtain the data needed to answer the specific problem the profile of the target respondents who would possibly respond to the problem stated. It is composed of a survey questionnaire distributed to randomly selected mothers who gave birth using stratified sampling methods from eleven barangays of the municipality.

\section{Data Gathering Procedure}

The researchers sought permission from 203 mothers. After, a request was granted from the Municipal Health Officer to allow me to administer the questionnaire. Lastly, the setting of the time frame in distributing and retrieving the instruments will be site. Analyzing data will be needed and data needed in the study

\section{Results and Discussion}

As seen from Table 1, mothers between ages 21 and 25 are the most strongly represented, with $32 \%$ of all respondents, 17 of 33 in this age group, or 39 of the total number are practicing mothers. It occupies $39 \% \mathrm{EBF}$, followed by mothers aged 26 to 30 years old 15 or $34 \%$ of 30 . Mixed feeding is also predominant in the 21-25-year-old group. Ages 14 years old out of 40 mothers given with mixed diet or 35\%. 15- 20 years old group of mothers follow. The age group is $26-35,13$ out of 40 or $33 \%$. $78 \%$ of mothers raising bottles are predominantly old raising bottles.

Table 1. Profile of the Respondents in terms of Age

\begin{tabular}{|c|c|c|}
\hline AGE & Frequency & Total \\
\hline $15-20$ & 25 & $24 \%$ \\
\hline $21-25$ & 33 & $32 \%$ \\
\hline $26-30$ & 30 & $31 \%$ \\
\hline $31-35$ & 10 & $9 \%$ \\
\hline $36-40$ & 3 & $4 \%$ \\
\hline $41-45$ & 1 & $2 \%$ \\
\hline TOTAL & 102 & $100 \%$ \\
\hline
\end{tabular}




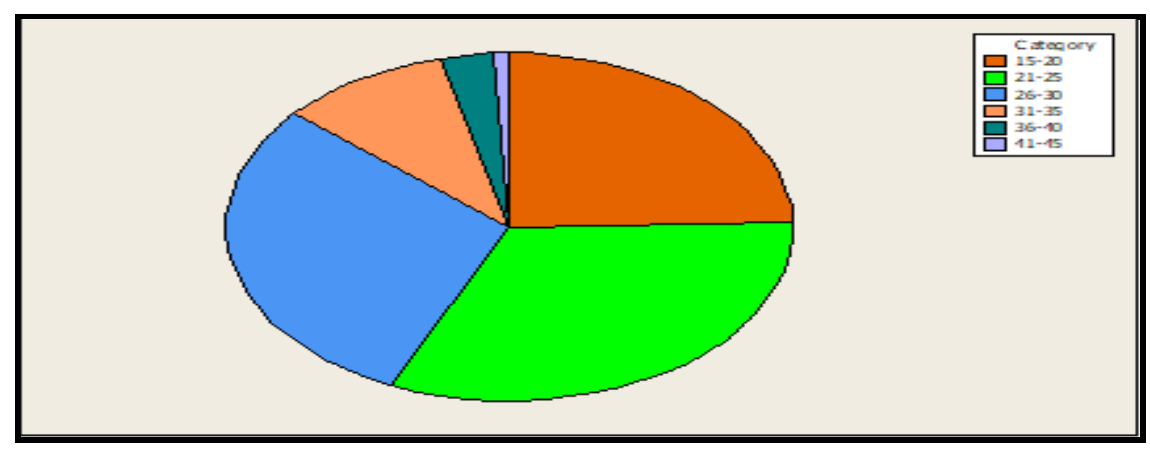

Figure1. Distribution of Profile of the Respondents in terms of Age

Table 2 shows the mother's profile for the number of living children. In the table above, respondents have children aged 1-3 (67\%), followed by mothers with 4-7 children (31\%), with children aged 8-11. It indicates that there are only two respondents. The results show that the more children the respondents have, the higher the percentage of respondents practicing EBF, followed by respondents who practiced $100 \mathrm{EBF}$ with 8-11 children, 47 children followed by $69 \%$ mothers, and 13 children. Mothers with 47 children predominantly mothers with mixed meals and bottles, 8 out of $32(25 \%)$.

Table 2. Profile of the Respondents in terms the Number of Living Children

\begin{tabular}{|c|c|c|}
\hline No. of children & Frequency & Total \\
\hline $1-3$ & 68 & $67 \%$ \\
\hline $4-7$ & 32 & $31 \%$ \\
\hline $8-11$ & 2 & $2 \%$ \\
\hline $12-15$ & 0 & $0 \%$ \\
\hline TOTAL & 102 & 100 \\
\hline
\end{tabular}

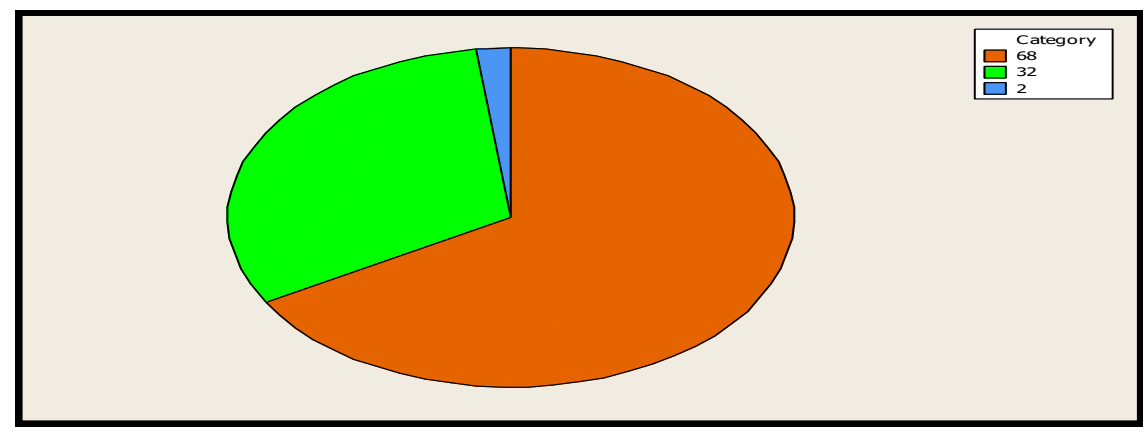

Figure 2. Representation distribution of Profile of the Respondents in terms the Number of Living Children

Table 3 shows the respondents' marriage status profiles. Of the 102 respondents, $56 \%$ or 55\% said they lived with a partner through a church wedding, a civil marriage, or a civil partnership. On the other hand, $45 \%$ or 46 mothers were single and, the study revealed they mere characterized as mothers with children but no spouse. The results show EBF practice in 38 of $56(67 \%)$ married mothers compared to $13 \%$ of single mothers. Mixed feed and bottle feeding are common among single mothers and give the following results: 25 out of 46 single mothers, or $54 \%$ and 14 out of 46 and $32 \%$, respectively. 
Table 3. Profile of the Respondents according to Marital Status of the Respondents

\begin{tabular}{|c|c|c|}
\hline Status of Mother & Frequency & Percentage \\
\hline Single & 46 & $45 \%$ \\
\hline Living in & 56 & $55 \%$ \\
\hline TOTAL & 102 & $100 \%$ \\
\hline
\end{tabular}

*Single includes with children but no spouse; being widowed

*Living in includes being married through church wedding, civil rights or in the state of cohabitation

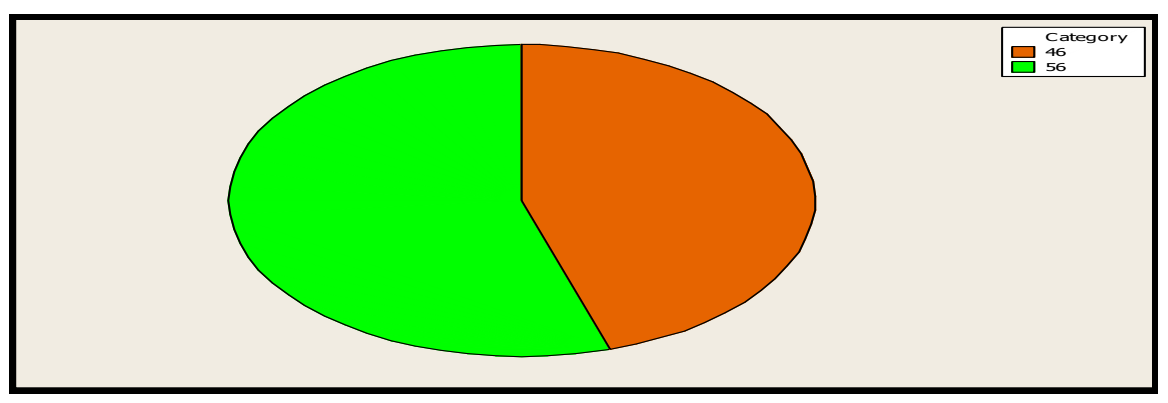

Figure 3. Profile of the Respondents according to Marital Status of the Respondents

Table 4 shows the mother's profile in terms of financial status. The results show that 43 out of $96(45 \%)$ low-income mother's practice EBF in 1 in $6(17 \%)$ middle-income mothers. Mixed feeding predominates in middle-income mothers, 4 out of $6(67 \%)$, compared with $38 \%$ in lowincome mothers. Bottle feeding is also predominant among 17 of 96 low-income mothers, or $18 \%$ of low-income mothers.

Table 4. Profile of the Respondents in terms of Economic Status

\begin{tabular}{|c|c|c|}
\hline Income Class & Frequency & Percentage \\
\hline Low Income Bracket & 96 & $95 \%$ \\
\hline Middle Income Bracket & 6 & $5 \%$ \\
\hline Upper Income Bracket & 0 & $0 \%$ \\
\hline TOTAL & 102 & $100 \%$ \\
\hline
\end{tabular}

*Low income includes P15, 780 and below

*Middle income includes monthly family income of P15, 781-P78,900

*Upper Income bracket includes monthly income of P78, 901 and above

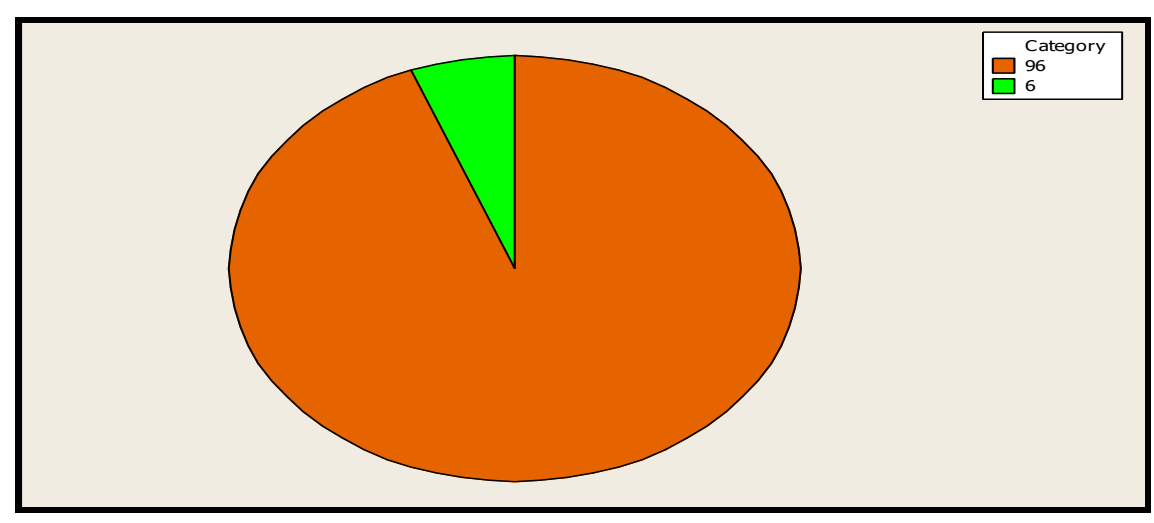

Figure 4. Profile of the Respondents in terms of Economic Status 
Table 5 shows the profile of respondents related to employment. The table shows that $77 \%$ of the respondents who participated said they had no job to handle the financial needs of their families. Out of 10 mothers work full-time in a private company. Conversely, four respondents said they worked for government agencies, but none said they worked part-time at private employers or offices (Frank \& Lewis, 2004).

Regarding work-based nutritional practices, 40 out of 79 (51\%) unemployed mothers have experienced EBF, followed by full-time employed mothers in private professions. Four out of ten mothers use baby bottles. Breastfeeding is common among full-time mothers in the state, with 3 in 4 or $75 \%$. Of the respondents working in public services, mixed feeding accounts for 6 out of 9 respondents or $67 \%$ of the total number of people working in public services.

Table 5. Profile of the Mothers in terms Employment Status

\begin{tabular}{|c|c|c|}
\hline Employment & Frequency & Percentage \\
\hline None & 79 & $77 \%$ \\
\hline Government-Permanent & 4 & $3 \%$ \\
\hline Government-Job Order & 9 & $8 \%$ \\
\hline Private-Fulltime & 10 & $12 \%$ \\
\hline Private-Part-time & 0 & $0 \%$ \\
\hline TOTAL & 102 & $100 \%$ \\
\hline & & \\
\hline & & \\
\hline & & \\
\hline
\end{tabular}

Figure 5. Profile of the Mothers in terms Employment Status

Table 6 shows the profile of respondents related to their education level. The table clearly shows that 40 mothers of $38 \%$ state that they have a college degree. An overwhelming number of 30 mothers reported having an elementary school degree, but only 16 reported having a college degree. No one said they had ever attended a school, vocational training, or elementary school diploma. Results based on education levels show that exclusive breastfeeding is more practiced by 19 out of $30(63 \%)$ primary school degree mothers and 21 out of 40 mothers (53\%). Showed they followed by a mother with a college degree. Graduation mothers are least likely to practice EBF in 1 in 14 (7\%), mainly because these mothers work in government and private offices.

Mixed feeding is a practice in 10 of 18 college-level mothers (56\%), 16 of 40 high school mothers (40\%), and 10 of 30 elementary school graduates (33\%). Baby bottle feeding was predominant between college graduates and college level, with the following results: 9 out of $14(64 \%)$ and 5 out of $18(28 \%)$. 
Table 6. Profile of the Mothers in terms of Educational Attainment

\begin{tabular}{|c|c|c|}
\hline Education & Frequency & Percentage \\
\hline None & 0 & $0 \%$ \\
\hline Elementary Under Grad & 0 & $0 \%$ \\
\hline Elementary Graduate & 30 & $29 \%$ \\
\hline High School & 40 & $38 \%$ \\
\hline College Level & 18 & $17 \%$ \\
\hline College Graduate & 14 & $16 \%$ \\
\hline Vocational Course & 0 & $0 \%$ \\
\hline Others & 0 & $0 \%$ \\
\hline TOTAL & 102 & $100 \%$ \\
\hline
\end{tabular}

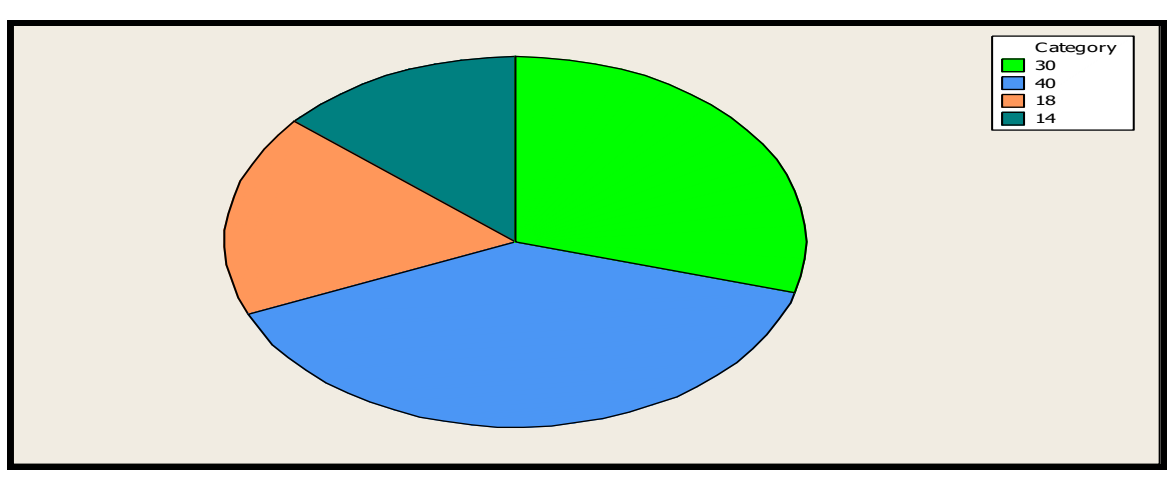

Figure 6. Profile of the Mothers in terms of Educational Attainment

Table 7 shows the mother's profile related to her current diet. The table shows that 44 of the 122 respondents stated that they were breastfeeding exclusively for their babies. Forty respondents said they prefer compound diets. Only 18 people feed their babies baby food. The penultimate result of these results is that most mothers do not contain non-breastfeeding foods, drinks, or even water, or (6) months of exclusive breastfeeding from the nanny, but the growth and development of the baby. It shows that you believe it is practical.

Table 7. Profile of the Mothers in terms their Current Feeding Practices

\begin{tabular}{|c|c|c|}
\hline Practices & Frequency & Percentage \\
\hline Exclusive Breast Feeding & 44 & $43 \%$ \\
\hline Mixed Feeding & 40 & $39 \%$ \\
\hline Formula Feeding & 18 & $18 \%$ \\
\hline TOTAL & 102 & $100 \%$ \\
\hline
\end{tabular}

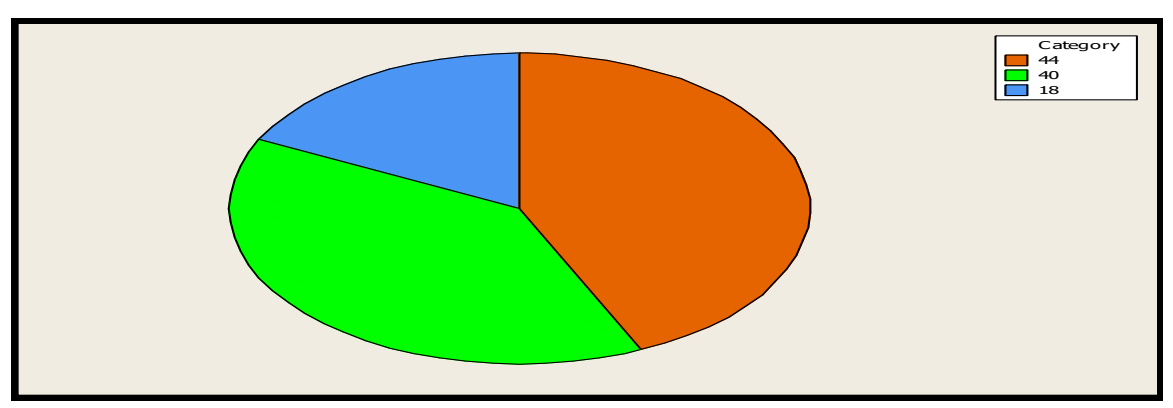

Figure 7. Profile of the Mothers in terms their CURRENT FEEDING PRACTICES 
Table 8 shows the mother's profile in terms of knowledge level regarding the importance of exclusive feeding. The results underscore the respondent's unimpressive perception of informed decisions. Sixty-four respondents (at least 63\%) reported little knowledge of the importance of exclusive feeding. Contrary to these results, only 38 people clearly stated that they were very familiar with the idea of feeding only 38 . The data effectively characterize respondents' preferences for the health and emotional benefits of exclusive breastfeeding from mother to child. This evidence is seemingly inadequate information and lobbying by rural health unit staff to warn mothers and other families of the importance of breastfeeding alone. Knowledge of the practicality of EBF in 6-month-old mothers has the basis and implications for the success and failure of government breastfeeding programs.

Table 8. Profile of the Mothers regarding the Level Of Knowledge On The Importance Of Exclusive Feeding

\begin{tabular}{|c|c|c|}
\hline Level of Knowledge & Frequency & Percentage \\
\hline None & 0 & 0 \\
\hline Little Knowledge & 64 & $63 \%$ \\
\hline Highly Knowledgeable & 38 & $37 \%$ \\
\hline TOTAL & 102 & $100 \%$ \\
\hline
\end{tabular}

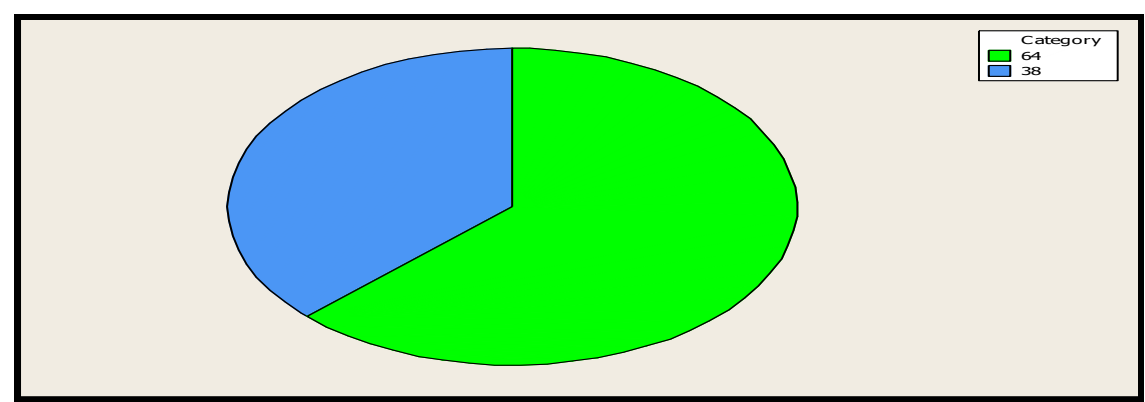

Figure 8. Profile of the Mothers regarding the Level of Knowledge on the Importance of Exclusive Feeding

\section{Conclusion}

About the age of respondents, mothers in the 21-25 age group are more likely to breastfeed alone. Mothers with 4 to 11 children practice breastfeeding only. Among married mothers, breastfeeding is often the only source. The results show that $43(45 \%)$ of 96 low-income mother's practice EBF. Regarding nutritional practices by employment status, the results show that 40 out of 79 mothers $(51 \%)$ are the majority of mothers who do not work solely on breast milk. Upon interpreting of the data, the result shows the levels of education of mothers, respondents who graduated from elementary school practice more exclusive breastfeeding. The majority of respondents are currently practicing breastfeeding. The majority of mothers know little about the importance of breastfeeding alone.

\section{Recommendation}

Proper breastfeeding is an effective way to reduce morbidity and mortality in children. Many mothers understand the importance of breastfeeding, but others are less aware of the benefits of breastfeeding and weaning. Its purpose is to continuously provide relevant information to all age groups, especially very young and poorly educated mothers, through bench meetings at the barangay level.

Proper breastfeeding starts at six (6) months old is essential for maximizing the growth, health, and development of a child. The first mother needs to understand the health message conveyed

Copyright $@$ 2021, Journal of Asian Multicultural Research for Medical and Health Science Study, Under the license CC BY-SA 4.0 
in the health class using the local dialect. Single mothers' perception of breastfeeding must attend with early counseling during their prenatal visit. Encourage family support through home visits by RHU staff or health center. As an incentive for low-income mothers to provide EBF to their children, such as enrolling in Philhealth, a free health check encourages mothers to be fully breastfed. The government should encourage employers to provide rooms in the office as a breastfeeding area to provide privacy to breastfeeding mothers. Timing and a proper schedule must be provided to the mother to ensure that the child is well nourished. Highly commendable that the nursery area must also be in place at the office during breastfeeding of a nursing mother with their baby. Importantly, breastfeeding benefits should be taught in grades 5 and 6 of elementary school to raise awareness. Government health services need to emphasize and support the importance of regular training programs for all rural health departments and hospital staff, especially those working in obstetrics and maternity wards.

\section{Conflict of Interest}

The authors declare no conflict of interest.

\section{Contributions from the Authors}

All the authors contributed to the realization of this work. All authors also declare that they have read and approved the final version of the manuscript.

\section{References}

Brown, S. J., Davey, M. A., \& Bruinsma, F. J. (2005). Women's views and experiences of postnatal hospital care in the Victorian Survey of Recent Mothers 2000. Midwifery, 21(2), 109-126.

Calderon C. (2003). National demographic health survey. Manila: National Statistics Office, 2003.The direction of causality between financial development and economic growth. Journal of Development Economics, 72(1), 321-334.

Frank, S. A., \& Lewis, G. B. (2004). Government employees: working hard or hardly working?. The American Review of Public Administration, 34(1), 36-51.

Kukla, R. (2006). Ethics and ideology in breastfeeding advocacy campaigns. Hypatia, 21(1), 157-180.

Lara-Cinisomo, S., McKenney, K., Di Florio, A., \& Meltzer-Brody, S. (2017). Associations between postpartum depression, breastfeeding, and oxytocin levels in Latina mothers. Breastfeeding Medicine, 12(7), 436-442.

Nadeem, J., Nadeem, A., Sarwar, M. H., \& Sarwar, M. (2017). Breastfeeding Benefit from Mom Gives the Gift of a Lifetime to the Baby for Healthy Future. American Journal of Food Science and Health, 3(5), 95-101.

Segura, S. A., Ansótegui, J. A., \& Díaz-Gómez, N. M. (2016). The importance of maternal nutrition during breastfeeding: do breastfeeding mothers need nutritional supplements?. Anales de Pediatría (English Edition), 84(6), 347-e1. 